\title{
Reflexiones sobre Karl Rahner desde América Latina. En el XX aniversario de su muerte*
}

\author{
Jon Sobrino, \\ Centro de Reflexión Teológica, \\ San Salvador.
}

En este artículo, quiero hacer algunas reflexiones sobre lo que Karl Rahner significó para mí, cuando en los años setenta surgía en América Latina una nueva Iglesia y una nueva teología Mis reflexiones son, pues, personales y, por lo tanto, limitadas, pero espero que puedan aplicarse de alguna forma al fenómeno más universal de la teología de la liberación, tal como me lo han pedido.

En el transfondo de estas reflexiones está la experiencia salvadoreña, desde la cual me tocó releer la teologia, que antes habra estudiado, incluida de manera muy importante, la de Rahner. También está mi estrecha relación, personal y teológica, con Ignacio Ellacuría, discípulo suyo, en Innsbruck (1958-1962), quien fue asesinado, junto con otros cinco jesuitas y dos trabajadoras de la universidad, el 16 de noviembre de 1989 , por su defensa de la fe y de la justicia'. Ellacuría, sin embargo, no sólo fue discípulo, sino que puso a producir, historizándolos debidamente para el mundo de los pobres, elementos importantes de la teología de Rahner'.

* El presente texto es la versión castellana, ligeramente reelaborada, de mi articulo "Gedanken aus Lateinamerika", publicado en Stimmen der Zeit, Spezial I - 2004, pp. 43 - 56. El número eslá dedicado a Karl Rahner a los cien años de su nacimiento y veinte de su muerte, el 30 de marzo de 1984. Los escritos de Rahner están citados en su traducción espariola, cuando ésta existe. Si no, están citados en la versión alemana original.

1. Véase "Compañeros de Jesús. El asesinato martirio de los jesuitas salvadoreños", 493-494, ECA (1989) 1041-1074.

2. Cfr. I. Ellacuría, "Tesis sobre posibilidad, necesidad y sentido de una teología latinoamericana", en Teologia y mundo contemporáneo: homenaje a Karl Rahner, edilado por A. Vargas Machuca, Madrid, 1975, pp. 325-350. 
Dos cosas queremos hacer en este artículo. La primera, en forma más descriptiva, es ofrecer la visión que tuvo Rahner de la novedad eclesial y teológica, en America Latina, en los últimos años de su vida. La segunda, en forma más analftica, aunque breve, es su influjo sobre la teología de la liberación.

\section{Ante la novedad eclesial y teológica latinoamericanas}

\subsection{Invierno eclesial y renovación en América Latina}

En la entrevista que concedió a Vida Nueva pocos días antes de su muerte, cuando le preguntaron qué pensaba sobre la situación de la Iglesia, Rahner contestó unas palabras que resultaron muy verdaderas: "en general, vivimos actualmente una etapa invernal", palabras que se siguen citando hasta el día de hoy como lamento y protesta. Pero añadió algo que, desgraciadamente, ha cardo en el olvido: "sin embargo, hay algunas regiones en la Iglesia, donde se da una vida carismática muy viva, que produce esperanza"3. Con ello se refería a la novedad de iglesias como las de América Latina, su testimonio, su praxis, su teología y también sus mártires. Al llamarlas carismáticas no las equiparaba a los movimientos carismáticos que hoy proliferan, sino a iglesias donde floreća el seguimiento de Jesús, la vida de comunidad y la libertad del evangelio - cristianamente más primigenia que la de la ilustración. En ellas afloraba un cristianismo libre, no anquilosado, animado y movido por el espíritu de Jesús. Y, por cierto, hay que preguntarse por que en los paŕses e iglesias de abundancia, estas palabras de Rahner, llenas de esperanza de lo nuevo, han quedado ignoradas, mientras se recuerda e insiste en "el invierno eclesial". De esa forma, no creo que se hace justicia a Rahner, ni a las iglesias del tercer mundo.

Esa esperanza que le producían las iglesias latinoamericanas la pude constatar personalmente. En marzo de 1979, en la Universidad de Marquette, Milwaukee, me preguntó con gran interés y cariño cuál habra sido el resultado de Puebla, si habŕa mantenido vivo a Medellín, o si reforzaba una marcha atrás, promovida ya en varias curias. En 1982, en la feria del libro de Franckfurt, le agradeci lo que había hecho por nosotros, y me contestó con modesta satisfacción que eso era lo menos que él podía hacer. Y es bien sabido que el 16 de marzo de 1984, dos semanas antes de su muerte, escribió una carta al arzobispo de Lima, Cardenal Landázuri, en defensa de Gustavo Gutiérrez, de su ortodoxia y de su teología, la cual, precisaba, ofrecía una gran novedad, pues estaba "al servicio de la evangelización concreta"4.

Algo hubo, pues, en las iglesias de América Latina que atrajo al Rahner, humano y cristiano. Creo que le atrajo una generación de obispos, sólo compara-

3. Entrevista reproducida en Diakonfa 30 (1984) 159.

4. Carta publicada en Diakonia 30 (1984) 168. 
ble a la de los primeros siglos de la Iglesia y a los del siglo XVI, en América Latina. "Obispos al estilo de un Helder Camara podéis serlo hoy con toda tranquilidad, porque arriesgariais la cabeza y el cuello por los pobres"s, escribfa en Palabras de san Ignacio a un jesuisa de hoy, en el apartado "Servir desde la falta de poder", presentándolo como obispo modelo, precisamente, para superar la letra de las normas de san Ignacio. No hay que desdeñar que, para interpretar actualizadamente el pensamiento de san Ignacio, recurriese a un ejemplo latinoamericano.

Y lo mismo hizo para ilustrar cómo había que comprender hoy el martirio. Se remitió a otro obispo latinoamericano:

¿Por qué no había de ser mártir un monseñor Romero, por ejemplo, caído en la lucha por la justicia en la sociedad, en una lucha que él hizo desde sus más profundas convicciones cristianas?

Indudablemente, una Iglesia con esos obispos le atrafa mucho. Y también, aunque fuera menos conocido para él, con sus agentes de pastoral, movimientos de sacerdotes, religiosos y religiosas. No sé cuánto conoció o intuyó Rahner la realidad de las comunidades eclesiales de base, pero pienso que captaría muy bien que lo más importante de ellas, como decía Ellacuría, es que son de base, están en la base de la realidad, con lo cual superaban el docetismo -ahora a nivel eclesial - al que tanto habla combatido Rahner a nivel cristológico. Y pienso que hubiese aplaudido lo que, desde la realidad latinoamericana, decía $I$. Ellacuría sobre lo decisivamente cristiano en una Iglesia que es también institución. "La Iglesia es madre y maestra, pero lo es por distintas razones. Más aún, hay prioridad de su carácter matemal sobre el carácter magisterial; es más importante su misión de dar vida o de transmitir vida que la de sancionar autoritativamente determinadas enseñanzas"?.

\subsection{Ante la teología de la liberación}

Pues bien, como es sabido, parte importante de esa novedad eclesial fue su momento teórico: la teología de la liberación. No creo que Rahner llegase a conocerla en detalle, pero sí intuyó lo fundamental y la apoyó. Y eso no hay que darlo por supuesto, pues otros grandes de su generación, Maritain, de Lubac, Urs von Balthasar, por ejemplo, no supieron qué hacer con lo nuevo que iba surgiendo. La teología de la liberación, en efecto, era un movimiento teologico nuevo, balbuciente y sin la profundidad conceptual de otras teologías postconciliares. Procedía de lugares lejanos y desconocidos para él, y su futuro era incierto. Era abrazada con entusiasmo por unos y criticada y perseguida por otros. Y se constituía también, en sí misma, con su insistencia en la praxis, los pobres y su liberación,

5. Publicado en Sal Terrae, Santander, 1979, p. 16.

6. "Dimensiones del martirio", Concilium 183 (1983) 323.

7. "Liberación", Revista Latinoamericana de Teología 30 (1993) 228. 
en pregunta crítica a las teologías europeas, incluso a las progresistas y postconciliares.

Que Rahner estuviese seriamente atento a esa teología, muestra una excepcional apertura, sobre todo si se tiene en cuenta que ya rondaba los setenta y tantos años, cuando ya han fraguado las estructuras psicológicas de la mente y el corazón, lo cual suele llevar más a preservar lo conseguido o a aceptar de forma reposada el nihil novum sub sole, que a la audacia de aceptar lo nuevo. Pero Rahner se decidió por lo segundo, como un Juan XXIII, quien cerca de los 80 , convocó un concilio, y como un Monseñor Romero, quien a los sesenta años llevó a cabo una revolución personal e institucional sin precedentes, en nuestros días".

Rahner no ignoró la novedad de esa teología, sino que la enfrento, y en 1977 escribió el prólogo al libro Befreiende Theologie". En él la defendfa, pero no sólo como teología regional, concentrada en y reducida al tratamiento de problemas éticos y sociales, sino como estricta teología. Le concedía, así, carta de ciudadanía.

La posibilidad para ello la veŕa en el pluralismo, que le es esencial a la teología, como repetía en sus últimos años. Y la necesidad se le fue imponiendo, al conocer cada vez más la realidad de injusticia y opresión como algo escandaloso, en el mundo, a pesar de la ilustración, en el mundo del saber, y de la democracia, en el mundo del poder político. Asumía también la dosis de "sana inseguridad", que esa teología podía producir en las teologlas europeas, deseaba que se entablara un serio diálogo entre ambas, y le exigía, por supuesto, que procediese como verdadera teología.

Por esas razones teóricas, defendió a la naciente teología de la liberación, pero quizás lo hizo también por la responsabilidad que sintió, en sus últimos años, de apoyar "causas perdidas" dentro de la Iglesia, y de ejercitarse en la vejez - con entusiasmo "juvenil"-, en lo que confesó que echaba de menos al volver su mirada a lo que había sido su vida, como dijo en la entrevista citada:

Me hubiera gustado que en mi vida hubiese habido más amor, más valentra, especialmente respecto a los que tienen autoridad en la Iglesia ${ }^{10}$.

Y recuérdese que Rahner lanzó un grito profético: Ich protestiere, "protesto", cuando el entonces arzobispo de Münich, Joseph Ratzinger, no permitió que J. B. Metz ocupase la cátedra de teología fundamental, en la facultad de teología católica. Y Rahner fue también uno de los pocos jesuitas que protestó cuando Juan Pablo II intervino la Compañía de Jesús, en 1982".

8. Cfr. Martin Maier, Oscar Romero, Meister des Spiritualität, Friburgo, 2001.

9. Befreiende Theologie. Der Beitrag Lateinamerikas zur Theologie der Gegenwart, editado por K. Rahner et al, Stuttgart, 1977, pp. 6-8.

10. Diakonia 30 (1984) 159.

11. Cfr. K. Rahner, "Zur Situation des Jesuitenordens nach den Schwierigkeiten mit dern Vatikan", en Schrifien zur Theologie, Bd. I5, pp. 355-372. 
Rahner, pues, tuvo un talante de apertura teológica y eclesial. Pero en lo que quiero insistir es en que esa apertura se expresaba no sólo en relación a temas "más europeos", por así decirlo, la evolución, las relaciones entre marxismo y cristianismo, el diálogo ecuménico, el desarrollo del concilio, etc., sino también en relación a algo más radicalmente novedoso, en el espacio y en el tiempo: lo que estaba ocurriendo en un continente lejano, tenido por subdesarrollado, en muchos aspectos, también en lo eclesial y teológico.

\section{El influjo de Rahner en la teología de la liberación}

Hemos visto que a Rahner le impactó la novedad latinoamericana. Veamos ahora el impacto de Rahner en la naciente teología de la liberación, en lo que consiste lo central de este artículo. Pero antes de analizarlo, quisiera precisar tres cosas.

La primera es recordar lo que Ellacuría decía sobre el proceso mental por el que pasó Rahner: de la postura del filósofo, presentada en Geist in Welt (1957), a la postura del teólogo fundamental y, de ésta, a la del teólogo dogmático. Pues bien, la teología de la liberación quedó influenciada por el Rahner de esta última etapa, es decir, por su comprensión -y comunicación - del acto revelador de Dios, lo que comprendía no sólo como lo verdadero - y obligatorio para la teología-, sino también como lo sumamente bueno para el ser humano. Si se me permite usar una expresión que suelo repetir, Rahner comunicaba que Dios es bueno y que es bueno que haya Dios. En ese sentido, pienso que su mejor teología fundamental fue su teología dogmática. Y junto con ésta, a América Latina llegó su teología y su talante espiritual (su librito Palabras al silencio lo he leído innumerables veces), y llegó también Ignacio de Loyola y sus ejercicios espirituales no como si Rahner fuera un propagandista ignaciano, peligro actual no del todo superado, sino como un convencido de lo benéfico de su experiencia espiritual-, de modo que uno de sus textos más logrados, en su época de madurez, es el ya citado Palabras de Ignacio de Loyola a un jesuita de hoy. Su influjo llegó, pues, a nosotros, a través de diversas dimensiones de su pensamiento y de su personalidad.

La segunda precisión es que lo que en los años setenta y ochenta se entendía por teología de la liberación, aun teniendo una importante base común, no era algo absolutamente homogéneo, y por eso, habría que analizar el influjo de Rahner. en Gustavo Gutiérrez y en Hugo Assmann, en Juan Luis Segundo y en Leonardo Boff. Nosotros vamos a generalizar su influjo, pero teniendo en cuenta que se trata de una generalización, y, como dije al principio, dejándome guiar con frecuencia por la recepción latinoamericana que de Rahner hizo Ignacio Ellacurfa.

La tercera precisión es que, en general, Rahner desbloqueó el camino a los teólogos de la liberación, lo cual fue un aporte importante, pero además les ayudo, de forma objetiva, probablemente sin saberlo, ni pretenderlo, a recorrer 
caminos nuevos, propios, latinoamericanos. De eso estoy convencido, pero no es tarea fácil para mí precisar con rigor en qué consistió ese aporte. Pienso que lo hizo sobre todo - además de a través de los contenidos fundamentales de su teología - a través de lo que podemos llamar el talante con que llevó a cabo el quehacer teológico, es decir, a través de una disposición existencial y mental de cómo abordar teológicamente la realidad. Rahner no fue maestro en cosas tan centrales para la nueva teología como la liberación o los pobres, pero su modo de abordar a Dios, desde el ser humano, y al ser humano, desde Dios, fue beneficioso para la naciente teología.

Lo que voy a hacer a continuación es simplemente mencionar, con un mínimo de análisis, algunos elementos importantes de la teología de Rahner y de la liberación, en los que se aprecia en varias cosas un talante convergente.

\subsection{La teología ante la realidad}

\subsubsection{El primado de la realidad}

De la teología de Rahner me impresionó que, aunque conocía bien cómo teologías y filosofías conceptualizaban la realidad, en lo fundamental era la realidad misma la que le movía a pensar y dirigía su pensamiento, conceptualizando después lo pensado con ayuda de las tradiciones teológicas y filosóficas. Esto puede parece obvio, pero no se suele notar con frecuencia en teologías que parecen conceptualizar más desde conceptos previos que desde la realidad. En cualquier caso, Rahner fue eximio en ello.

No sé si exagero, pero su teología puede ser comprendida como servicio a algo importante que escribí, en su conocido artículo sobre la teología del símbolo: "la realidad quiere tomar la palabra"'2. Pienso que, para él, hacer teología no era otra cosa que "elevar la realidad a concepto", aunque necesitase de conceptos para que se diese dicha elevación. Recuerdo que sobre eso solíamos hablar Ellacurfa y yo. Por ello, en medio de hondas especulaciones, Rahner tenía la virtud de comunicar el sabor a realidad, un sapere que es sapiencial, pero no sólo eso, sino que es el gusto que tiene la realidad, cuando uno se enfrenta con ella, se encarga de ella y carga con ella, como decfa Ellacuria - a lo que añadimos nosotros y se dejar cargar por ella.

Desde esta perspectiva, quisiera ahora simplemente recordar, sin analizar, algunas frases de Rahner, producto de mucho pensamiento teórico, sí, pero que no parecen ser conclusión de un proceso meramente teórico, sino puesta en palabra de lo más hondo de una realidad confrontada. Son frases lapidarias, no

12. Cfr. "Para una teología del símbolo", en Escritos de teologia $N$, Madrid, 1964, pp. 283-321. 
por el artificio que puede haber en su formulación, sino porque parecen extraídas de la roca de la realidad.

Sobre la última verdad de la teo-logía, decía que "la teología católica sólo dice una cosa: que el misterio permanece misterio etemamente" 13 . Sobre el cristianismo decía: "Creo que ser cristiano es la tarea más sencilla, la más simple, y a la vez, aquella pesada carga ligera de que habla el evangelio. Cuando uno carga con ella, ella carga con uno, y cuanto más tiempo viva uno, tanto más pesada y más ligera llegará a ser. Al final, sólo queda el misterio. Pero es el misterio de Jesús"'14. Sobre el futuro del cristianismo decía: "el cristiano del futuro o será un 'mistico', es decir una persona que ha 'experimentado' algo, o no será más cristiano"15, palabras hoy muy recordadas. $Y$ estas otras no tan recordadas (pues no parece estar de moda tomar el pecado en serio): "sólo el perdonado se sabe pecador". $Y$ aunque no parezca de gran hondura teológica, también recuerdo el "así no puede ser"16 con que comenzaba su primer gran artículo sobre la Trinidad, ante la inanición del pensamiento trinitario al uso. Rahner pensaba, rumiaba, argumentaba, pero el final del proceso, no era meramente una conclusión a la cual había llegado por pasos lógicos, ni la coronación de un discurso racional, sino que era más bien una proclamación de la realidad, que tomaba la palabra.

Mutatis mutandis, creo que ese dar primacía a la realidad dentro del pensar y del pensar teológico también ocurrió en los momentos fundantes de la teología de la liberación. No empezó con conceptos, ni con las mejores conclusiones teológicas adquiridas, sino con la realidad. En formulación ignaciana, quizás pueda decirse que en esa realidad - la irrupción del pobre - encontró un fundamento sobre el cual edificar el pensar teológico, que fue fundamento dinámico, principio, que mantenía el fundamento, a lo largo del proceso teórico.

Digámoslo más en concreto. Decir que los pobres -y Dios en ellos - han irrumpido en la historia es la afirmación fundamental de realidad para la teologia de la liberación. Y de ahí, las consecuencias: a esta irrupción objetiva debe responder y corresponder el sujeto creyente (y humano), liberándolos, bajándolos de la cruz ${ }^{17}$, y la teología no puede ser ideología, que favorece a la opresión. Nada de eso es meramente conclusión teórica extrapolada, sino que es

13. Cfr. "Sobre el concepto de misterio en la teología católica", en Escritos de teología IV, pp. 53-101.

14. Karl Rahner y K. H. Weger, ¿Qué debemos creer todavía? Propuestas para una nueva generación, Santander, 1980, p. 190.

15. "Espiritualidad antigua y actual", en Escritos de reologia VII, Madrid, 1968, p. 25.

16. "Advertencias sobre el tratado dogmático 'de Trinitate", en Escritos teologicos $I V$, p. 117.

17. Cfr. I. Ellacuria, "Las iglesias latinoamericanas interpelan a la Iglesia de España", en Escritos teológicos II, San Salvador, 2000, p. 602. 
dar, indefensa y esperanzadamente, primado a la realidad, dejarla hablar, escuchar su palabra, dejarse guiar por ella y responder a ella.

$Y$ escandalosa y novedosamente - aunque eso aparezca más en la teología de la liberación que en la de Rahner-, también es dar primado a la realidad, aceptar que en esos pobres hay salvación, que cargan con nosotros, nos ofrecen luz sobre nosotros mismos y sobre Dios, y de forma inmerecida e inesperada, mantienen la esperanza La teología de la liberación no deduce esto de conceptos previos - aunque los utiliza -, sino que lo produce desde el enfrentamiento primario con la realidad. "La gloria de Dios es el pobre que vive". "Ustedes - pobres y víctimas - son hoy el siervo doliente de Yahve, el pueblo crucificado". "La Iglesia es Iglesia de los pobres". "Los pobres nos evangelizan". Estas son frases lapidarias, proclamaciones de la realidad, de Mons. Romero, de Ignacio Ellacuría, de Puebla. Poseen la radicalidad y la indefensión de las citadas de Rahner.

\subsubsection{La realidad como misterio}

Esa realidad mentada lleva en su seno un misterio. El misterio por antonomasia es Dios, y el ser humano es el ser ante el misterio. En Rahner, esto es evidente y absolutamente central.

En el fondo hay un sólo misterio: que la incomprensibilidad de Dios, en la que él es Dios, se nos da no sólo como la lejanía y el horizonte en los que se mueve nuestra existencia ${ }^{18}$.

Rahner insiste en que Dios es el misterio santo, que sin dejar de ser misterio, se ha acercado absolutamente, rompiendo para siempre la simetría de ser posiblemente salvador o posiblemente condenador: Dios es por esencia salvador. Esa verdad de un Dios salvador esencial está presente en toda su teología, su concepción de Cristo, la Iglesia y los sacramentos, y hasta en detalles en los que normalmente no se suele reparar, pero que expresan la profundidad y dinamicidad de esa convicción. Asĺ, dice, por ejemplo, que la Iglesia de ese Dios, por su afinidad con ese Dios, puede canonizar, es decir, puede declarar dónde hay salvación absoluta, pues es lo suyo; pero no puede condenar, es decir, declarar donde hay condenación absoluta.

Esta centralidad del misterio y de Dios, más honda que en las teologías al uso y en otras progresistas, está también presente en la teología de la liberación, la de Gustavo Gutiérrez, ciertamente: pone en su centro el misterio y el misterio de $\operatorname{Dios}^{19}$. Sin buscar paralelismos artificiosos, creo que la teología de la liberación capta al pobre como misterio, de modo que éste aparece como realidad no

18. Karl Rahner, "Misterio", en Sacramentum Mundi IV, Barcelona, 1973, p. 715.

19. Cfr. Gustavo Gutiérrez, "Una teología de la liberación en el contexto del tercer milenio", en El futuro de la reflexión teologica en América Latina, Bogotá, 1996; Densidad del presente. Selección de articulos, Lima, 1996, p. 350. 
sólo en un ámbito concreto, con exigencias éticas, por ejemplo, ni siquiera sólo - aunque esto es más ignorado- con un potencial salvífico, sino que aparece como realidad misteriosa.

La imupción del pobre -y de Dios en él- tiene múchas de las características con que Rahner describe el misterio. Digámoslo muy brevemente: el pobre es el otro lejano, inmanipulable, y es, además, el diferente, por estar oprimido y es el interpelante, por lo tanto. Pero es también el otro cercano, salvador, el misterio santo - como Dios-, con todas las analogías del caso. De ahí que Ellacuráa escribiese sobre el pueblo crucificado como la presencia del misterio de Dios, pero, además, comprendiese esa presencia como salvífica. Hablaba, en forma desconocida, de soteriología histórica ${ }^{20}$.

\subsubsection{Lo sacramental de lo real}

En ello insistía Karl Rahner. La realidad es de suyo simbólica. Busca expresarse y tomar la palabra. Es conocido el avance esencial que Rahner, con otros como $\mathrm{O}$. Semmelroth, dio a la concepción de la Iglesia como sacramento y a los sacramentos concretos como expresión de esa sacramentalidad primigenia. Pero con anterioridad lógica y metafísica está la sacramentalidad de Jesús de Nazaret. Baste recordar la genial interpretación de la encarnación, insistiendo en que Dios "devino hombre", que la sarx de Cristo no era ropaje, sino el modo que tiene lo divino para aparecer, en nuestro mundo ${ }^{21}$, a lo que Ellacuría añadía, al comentar la frase de Rahner, en nuestro mundo "de pecado", es decir, un devenir sarx, no sólo como abajamiento metafísico, sino como abajamiento a la realidad histórica, que da muerte.

Sobre este Jesús, sacramento del Padre, concreción y manifestación del misterio de Dios, escribió probablemente sus páginas más bellas. En sus Palabras al silencio así expresaba Rahner, poéticamente, la sacramentalidad de Cristo al hablar de Dios:

De tu mar solamente debra venir el rocío de tu suavidad sobre mi exiguo campo. En palabras humanas viniste a mí, porque tú, infinito, eres el Dios de Nuestro Señor Jesucristo. El nos habló en palabras humanas, y ya no habrá de significar la palabra del amor lo que yo pudiera temer, porque cuando él dice que él, y tú en él, nos amas, entonces proviene esta palabra de un

20. Cfr. 1. Ellacurfa, Conversión de la Iglesia al reino de Dios para anunciarlo y realizarlo en la historia, San Salvador, 1984, especialmente pp. 25-63; "El pueblo crucificado", en Mysterium Liberationis. Conceptos fundamentales de la Teologia de la liberación II, editado por I. Ellacuría y J. Sobrino, San Salvador, 1991, pp. 189 - 216.

21. Cfr. Karl Rahner, "Para una teologfa del símbolo", en Escritos de teología $N$, pp. 303. 
corazón de hombre. Y en un corazón de hombre, tal palabra sólo tiene un significado, sólo un significado bienhechor ${ }^{22}$.

De ahi que hablase también de "la eterna significación de la humanidad de Jesús para nuestra relación con Dios"23, es decir, de la importancia de lo sacramental para que la realidad pueda ser mediación de nuestra relación con el misterio último.

Se ha hecho notar que la teología de la liberación no ha elaborado una sacramentología, como lo advierte V. Codina y J. M. Castillo. Sin embargo, la idea de la sacramentalidad fontanal de la realidad está presente. Leonardo Boff hablo de la sacramentalidad de Cristo, en palabras igualmente bellas: "Así de humano sólo puede ser Dios"24. Y el énfasis y el modo de explicar cómo la humanidad de Jesús es sacramental llevó a la idea, muy querida por Ellacuría, de la transcendencia en la historia.

Central en la teología de la liberación es la presencia de Dios en los pobres, lo que implica también la posibilidad y necesidad de hacer convergir, por ejemplo, mistica y política, transcendencia e historia. De esta forma, la teología de la liberación pueda tomar absolutamente en serio la historia, en diferenciación, pero no en distanciamiento y menos en oposición, a lo teologal. Los slogans contra la teología de la liberación - la mayor parte de las veces sin fundamento- de que es sociología y no teología deben ser revisados, a partir de lo dicho: la historia puede ser sacramento de Dios. Más en concreto y cristológicamente, el pueblo crucificado es, a la manera de siervo, el sacramento de Dios, como repitieron Monseñor Romero e Ignacio Ellacuría.

La visión sacramental de la realidad ayudó también a la concepción de la relación entre transcendencia e historia, una transcendencia no más allá de la historia, sino en la historia. De esa forma, la historia, la de Dios y la de los humanos, se convierte en una única "gran historia de Dios"2s.

Rahner abordó el terna, en un artículo importante "Historia del mundo e historia de la salvación"26, buscando su relación y su unidad. Y también ayudó a esta intuición, aunque fuese indirectamente, su teologoumenon del "existencial sobrenatural". En directo, el problema trata de la relación entre gracia y naturaleza, pero en el fondo, toca el problema de si existe una única realidad, siempre agraciada, desde la perspectiva de Dios, aunque siempre pueda ser rechazada, desde la libertad humana. La teología de la liberación insiste en que hay una

22. Karl Rahner, Palabras al silencio, Estella, 1991, p. 29.

23. En Escritos de reologia III, Madrid, 1961, pp.47-59.

24. Jesucristo el Liberador, Buenos Aires, 1976, p. 187.

25. Cfr. I. Ellacura, "Historicidad de la salvación cristiana", en Revista Latinoamericana de Teologia 1 (1984) 5-45.

26. En Escritos de teología V. pp. 115-134. 
sola historia, cuyas dos dimensiones no están adecuadamente descritas como naturaleza y gracia, historia profana e historia de salvación, sino como historia de gracia e historia de pecado.

\subsection{El quehacer teológico como acción del sujeto}

Hemos visto muy someramente qué es la realidad sobre la que versa el quehacer teológico. Veamos ahora algunas dimensiones de ese quehacer.

\subsubsection{La lógica existencial}

Insistía Rahner en que Dios puede dar y darse a conocer, él y su voluntad, en lo novedoso y concreto, en lo indeducible a partir de cualquier otro conocimiento previo, y eso puede ser captado como proveniente de Dios. La realidad que toma la palabra puede ser conocida, pues, en su indeducibilidad ${ }^{27}$, y puede ser reconocida como de Dios. Es evidente que ambas cosas, indeducibilidad para el discurso teológico y de Dios, no solían ser tenidas en cuenta.

Cierto es que el Concilio apunta a ambas cosas, al hablar de los signos de los tiempos. Pero hay que recordar que la acepción tiene dos sentidos: un sentido historico-pastoral, "como lo que caracteriza a una época" (Gaudium et Spes, 4), importante por supuesto, pero todavía no decisivo. Y un sentido historico-teologal: como "acontecimientos, exigencias y deseos... los signos verdaderos de la presencia o de los planes de Dios" (Gaudium et Spes, 11), lo cual es comúnmente más ignorado. La indeducibilidad para el pensamsiento puede estar presente en ambos sentidos, pero el ser de Dios, sólo en el segundo.

Pues bien, este modo de reconocer la presencia de Dios en la historia - lógica existencial, discernimiento de los signos de los tiempos-, afín al reconcimiento de la voluntad de Dios de que habla Rahner, no deducible de principios universales, pertenece también a la esencia de la teologfa de la liberación. La tesis fundamental de Gustavo Gutiérrez ha sido, desde el comienzo, que no sólo hay que mirar al pobre, hacer una opción, etc., sino que en la historia "ha imumpido" el pobre, con sus sufrimientos y esperanzas, $y$, juntamente con $e l$, ha imumpido Dios $^{28}$. Y esa irrupción ha sido captada, en su concreción indeducible. Una vez captada, la irmupción puede y debe ser cotejada con textos previos de la Escritura, de la tradición y de las teologías, y puede y debe ser esclarecida por la filosofía y las ciencias sociales. Pero la captación primordial es otra cosa. Pertenece a la lógica existencial del ser humano: "ha imumpido el pobre", y a la lógica existencial del creyente: "y Dios en él". Y a esa lógica existencial, que puede ser ilustrada por reflexiones sobre la realidad, en la teología de la libera-

27. Cfr. "La lógica del conocimiento existencial en san Ignacio de Loyola", en Lo dinámico en la Iglesia, Barcelona, 1963, p. 93-181.

28. Cfr. Gustavo Gutierrez, La fuerza histórica de los pobres, Lima, 1979. 
ción también pertenece la reacción primigenia, formulada como esperanza y praxis, liberación de los pobres de todo tipo de opresiones, y como la opción por los pobres.

La captación de que "Dios ha irrumpido en el pobre" - la radical novedad de la teología de la liberación-, bien podía encontrar fundamento y eco a la vez, sin chirriar, en una teología como la de Rahner, aunque sí chirriaba estrepitosamente, en lo que entonces se llamaba la teología al uso.

\subsubsection{La teología como reductio in mysterium}

Por ser Dios misterio, la teología es siempre para Rahner reductio in mysterium, lo cual quiere decir, que todas las realidades teologicas pueden y deben ser remitidas a Dios, como al misterio único, del cual cobran inteligibilidad y significatividad. Las diferencias entre ellas dependen de su diversa relación con dicho misterio (en la línea de lo que dice el Vaticano II de la jerarquía de verdades, $U R$ 11). Y esto debe ser tenido en cuenta y convertirse en algo central, en el quehacer del sujeto teológico.

Personalmente, pienso que la teología de la liberación procede de manera parecida o análoga en el tratamiento de los pobres. No quisiera caer en fáciles paralelismos, pero si Dios está en el pobre, se podrá hablar del pobre con una lógica análoga a como se habla de Dios. Teniendo en cuenta todas las cautelas necesarias, si pienso que se puede hablar - como lo hace la teología de la liberación - de la ultimidad del pobre, de la posibilidad de que la opción por el pobre configure la totalidad del ser humano (qué puedo saber, qué tengo que hacer, qué me es lícito esperar y celebrar) y que la teología pueda operar una especie de reductio in pauperes.

AsÍ, sin violentar la fe, ni manipular a los pobres, la teología puede hablar de la Iglesia como esencialmente Iglesia de los pobres, puede hablar del potencial evangelizador de los pobres, como dice Puebla, puede crear teologoumena como extra pauperes nulla salus...Y por supuesto, puede ver en el pobre la realidad ante la cual se decide la humanidad o la inhumanidad de nuestra existencia, la salvación o la condenación eternas.

Lo primero quiere decir que, ante los pobres, vivir como salvados significa trabajar por su liberación, "bajar de la cruz a los pueblos crucificados", que decía Ellacurfa. Y lo segundo quiere decir que ellos nos juzgarán, en el día del juicio. Juan Pablo II, en su viaje a Canadá, en septiembre de 1985, lo dijo gráficamente: "los países pobres juzgarán a los países ricos", a lo que hay que añadir que, en muchas ocasiones - ésa es mi experiencia, en El Salvador-, los pobres también nos otorgan perdón, con lo cual, por cierto, se capta más fácilmente la intuición de Rahner: "sólo el perdonado se sabe pecador". 
En los pobres hay ultimidad, no sé si metafísica, pero sí, ciertamente, funcional: no se puede ir más allá de "la autoridad de los que sufren"z2, que dice Metz, como no se puede ir más allá de la re-acción de la misericordia ante las víctimas ${ }^{30}$.

\subsubsection{Teología y espiritualidad}

Digamos, para terminar, que el quehacer teológico debe estar transido no sólo de saberes y de praxis-, sino de espiritualidad, lo que Rahner dijo con toda claridad:

En mi teología es fundamental el hecho de una verdadera y originaria experiencia de Dios y de su espíritu. Esta precede logicamente (no necesariamente cronológicamente) a la reflexión y verbalización teológica y nunca puede ser alcanzada adecuadamente por la reflexión ${ }^{3 !}$.

Esta experiencia personal de Dios es presupuesto existencial de su teología, lo que es evidente, en sus palabras, pero es también presupuesto metodológico. Es, si se quiere, punto de partida y de llegada de la teología. En ese sentido, la experiencia de Dios sería como el método considerado en su acepción original: el caminar del ser humano (en este caso, del teólogo pensante) hacia Dios (el objeto de la teología). Dentro de este método fundamental y más abarcador habrá que comprender los métodos categoriales; en Rahner, el método transcendental, y el uso ecléctico de otros modos de pensar. Pero en mi opinión, según Rahner, éste vive de aquél, y no a la inversa.

También en este doble sentido, existencial y metodológico, la teología de la liberación presupone una experiencia espiritual. Se dijo desde el principio, y Gustavo Gutiérrez insiste hasta el día de hoy: "nuestra teología es siempre un acto segundo, a la que precede la experiencia de la fe y la práctica de libera-

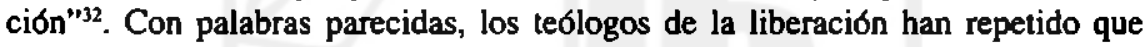
"nuestra teología es nuestra espiritualidad"33. Esto es asi, hasta tal punto que, de la teología de la liberación, se ha dicho a veces que abunda en fe (espiritualidad), pero no en ciencia, lo cual puede ser más o menos verdad, según los casos. Pero en principio, pienso que los mejores teólogos hacen que la experiencia espiritual, la experiencia de Dios, guíe también cientlficamente su quehacer teo-

29. J. B. Metz, "Die Autorităt der Leidenden", en Prinzip Mitgefühl, editado por L. Boff, Friburgo, 1999, pp. 43 s.

30. Cfr. J. Sobrino, "Teología en un mundo sufriente. La leología de la liberación como 'intellectus amoris"', en Revista Latinoamericana de Teologia 15 (1988), pp. 243 266.

31. Karl Rahner im Gespräch II: 1978-1982, editado por P. Imhof y H. Biallowons, Munich, 1983, p. 257.

32. Cfr. G. Gutierrez, Hablar de Dios desde el sufrimiento del inocente, Salamanca, 1988, pp.17-18.

33. Cfr. G. Gutiérrez, "Un lenguaje sobre Dios", Concilium 191 (1984) 53-61. 
Iógico. En este contexto, Ellacuría solía recordar estas palabras de Zubiri: "El acto o los actos de acceso del hombre a Dios no son los formalmente intelectivos, sino que son aquellos actos que física y realmente nos llevan efectivamente a $\mathrm{El}$ como realidad absolutamente absoluta".

\subsection{Las diferencias}

En lo que acabo de decir, noto el influjo fundamental de Rahner, en la teología de la liberación. No es, la mayorfa de las veces, un influjo en los contenidos, aunque muchos de ellos fueron aceptados. Tampoco es un influjo directo, en la temática más específica de la teología de la liberación: pobres y liberación, más la teo-logía, la cristo-logía y la eclesio-logía, que de ahí se deducen. Es, más bien, un aporte indirecto, pero eficaz.

La naciente teología encontraba inspiración y justificación teológica en su modo de proceder, en estas intuiciones de Rahner, aunque él no hablase de liberación ${ }^{34}$, y en su modo de proceder con relación a otras teologías de su tiempo. El influjo se dio sobre todo a nivel de lo que he llamado talante teológico: creatividad, libertad, responsabilidad histórica, en el mundo de hoy, y evangelicidad - perdóneseme la expresión-, es decir, mantener a Jesús como norma normans, non normata, ante realidades importantes. Lo que hemos intentado hacer es mostrar la convergencia de talantes, en dar primado a la realidad, en la ultimidad del misterio, en la lógica existencial, en la fundamentalidad de la espiritualidad.

Obviamente, hay diferencias. Rahner se movió en el mundo de la ilustración, simbolizada en Kant, y la teología de la liberación se movió en el mundo de la ilustración, simbolizada en Marx ${ }^{33}$. Lo común es que ambas teologfas intentaron responder con el máximo de responsabilidad a ambos desaf́os.

Y visto desde la de la liberación, hubo también lagunas importantes, en la teologia de Rahner. No analizó la praxis como dimensión del conocimiento teológico, no historizó la salvación como liberación histórica. Más sorprendentemente, mientras insistio - genialmente - en la encamación de Cristo, no insistió de igual manera en la cruz de Jesús. Ya vimos al principio cómo, en sus últimos años, le impactaba más la realidad del mundo, pero sin introducirla en un esquema teológico. Honrado con lo real, sin disimular la realidad de la Iglesia, sin permitir que su pensamiento fuese ideologizado, tampoco se puede llamar profética a su teología, aunque hacia el final, sí expresó la dimensión utópica del cristianismo.

34. Por lo que conozco, este influjo se nota sobre todo en la teología de Ignacio Ellacurfa. Véase el artículo de Martin Maier, "La influencia de Karl Rahner en la teologia de Ignacio Ellacurfa", Revisfa Latinoamericana de Teologla 39 (1996) 233-255 y 44 (1998) 163-187.

35. Cfr. J. Sobrino, "El conocimiento teológico en la teología europea y latinoamericana", ECA 322-323 (1975) 426-445. 
Su gran amigo y discípulo J. B. Metz, cuenta que le reprochaba: "Karl, ¿cómo puedes hacer teología sin tener en cuenta a Auschwitz?". Y pienso también que no llegó a vislumbrar la utopía de Ellacuría de una "civilización de la pobreza"36, con fundamentos históricos y hondamente evangélicos - y también ignacianos, según la meditación de las dos banderas-, contraria a la "civilización de la riqueza", que ni ha dado vida a las mayorías, ni ha humanizado.

Personalmente, pienso que Rahner hubiese abordado estos o algunos de estos temas, pero no fue su época. De todas formas, recuérdese lo que dijimos al principio sobre su apoyo a una Iglesia y una forma de ser cristiano que iba surgiendo en América Latina. En ella eran centrales varios de los temas que aqur hemos echado de menos, en su teología. Como en germen, desde su trayectoria y a su modo, pienso que como persona y, por lo tanto, como té́logo, pues en él no se separaban fácilmente ambas cosas, se encaminaba, dicho sin demagogia, hacia lo mejor de la teología de la liberación, a la cual también hubiera dirigido su palabra crítica y animante.

\section{Sumergirse en el misterio de Díos}

Para terminar, ya que estamos recordando el centenario de un nacimiento y veinte años de su muerte, es decir, el recuerdo de una persona, no sólo de un teólogo, volvamos a lo más personal de Karl Rahner.

No me atrevo a precisar dónde se encuentra eso "más personal", pero quizás se pueda decir algo a partir de lo que escribió, en sus últimos años: "El cristiano del futuro será místico o no será", decía, lo cual fue cariñosamente retocado por Pedro Casaldáliga: "el cristiano del futuro será pobre o solidario con los pobres, o no sera". Su discípulo Metz añadra a la "mística" la "política", y, como es bien sabido, en America Latina, Gustavo Gutiérrez hablaba de "contemplar" y "practicar" a Dios. Pero siempre queda en pie el momento "místico" de la persona de Rahner.

De forma muy personal, solía escribir dónde estaba "el pozo" del cual bebía, en último término:

La espiritualidad de Ignacio que recibimos por medio de la praxis de la oración ha sido más importante para mi que la filosofía y la teología más sublimes, tanto dentro como fuera de la Iglesia ${ }^{37}$.

Dejemos, pues, a Rahner con el anhelo de "mística" para ser cristiano y humano. Pero antes de terminar, quisiera añadir una pequeña nota personal. Mi primer encuentro con Rahner no fue ni en el aula como alumno suyo, ni en una biblioteca, como estudiante de teología, que tiene que preparar una tarea. Estudiaba filosofla, en los años sesenta, en Sant Louis University, y en medio de los avatares

36. Cfr. I. Ellacuria, "Utopfa y profetismo", en Mysterium Liberationis I, San Salvador, 1991, pp. 393-442.

37. Karl Rahner im Gespräch, p. 51. 
existenciales de aquellos años, dudas, sospechas, amenazas a la fe, me encontré, por casualidad, con un libro de un tal Karl Rahner, totalmente desconocido para mí. El libro resultó ser Sentido teológico de la muerte $e^{38}$. Me impactó todo él y me llevó a leer más escritos de aquel teólogo que acababa de conocer. Así conocí a Karl Rahner. Después, leí y estudié muchas otras cosas suyas. Pero nunca he olvidado aquel libro suyo sobre la muerte. Por eso, para terminar, quisiera recordar dos cosas que aquí, en El Salvador - no así en muchos otros lugares-, son fundamentales, artículos stantis vel cadentis ecclesiae, que se decla antes.

La primera es que Rahner dice, en el libro, que el martirio es "la muerte cristiana por excelencia" $-\mathrm{y}$ cuántas veces he tenido ocasión de enfrentarme con esa frase aquí, en El Salvador. Por lo que toca al mismo Rahner, no sé exactamente a qué experiencia suya personal respondía tal afirmación, o si era una de tantas formulaciones dogmáticas profundas suyas. Pero quizás fuera algo más. En ese sentido, siempre me impresionó, después, cómo hablaba de su amigo y hermano jesuita Alfred Delp (1907-1945) ${ }^{39}$, quien firmo su definitiva incorporación a la Compañía con las manos esposadas, antes de ser ejecutado, por los nazis, por su cooperación en el Kreisauer Kreis. Que Rahner nunca olvidó al padre Delp, mártir de los nazis, es una de las cosas que más aprecio en su persona.

La segunda es su visión de la muerte, y quisiera retomar sus palabras iniciales, en la entrevista citada al comienzo de estas líneas. Dice mucho de su persona y del talante de su teologfa:

La auténtica cima de mi vida está aún por llegar. Es el abismo del misterio de Dios, en que uno se precipita con la esperanza de ser acogido eternamente por su amor y su misericordia ${ }^{40}$.

"Cima", "por llegar", "misterio de Dios", "ser acogido eternamente por su amor y su misericordia". ¿Hay aquf teología de la liberación? Obviamente, el análisis de la respuesta no es lo más importante. Pero me gustan las palabras con que don Pedro Casaldáliga, cristiano, obispo y poeta de la liberación, comenta la muerte de Rahner:

- ¿Qué estŕs haciendo ahora?

Le preguntaba el Papa (¿inquisidor? ¿benévolo?).

Respondla el teólogo (¿evasivo? ¿maestro?):

- Me preparo a vivir el gran Encuentro.

$\mathrm{Y}$ a sus 80 abriles bien pensados, oyente del Misterio en la Palabra, se ha zambullido en el total Futuro ${ }^{41}$.

38. Barcelona, 1975.

39. Cfr. "Karl Rahner Einleitung zu den Texten", en A. Delp, Gesammelt Schriften I, editado por R. Bleinstein, Frankfurt, 1982, pp. 43-50.

40. En Diakonta, p. 158.

41. "Salmo de Brasil en Sao Paulo", en El tiempo y la espera, Santander, 1986, p. 39. 